\title{
Preliminary study on Coupling numerical model of hydrology and hydrodynamics for The Typical Area of Pearl River Delta
}

\author{
XUE Jiao*, LIAO Xiaolong, WU Leping, HOU Guibing \\ China Water Resources Pearl River Planning Surveying \& Designing Co.,Ltd., Guangzhou 510610, Guangdong, China
}

\begin{abstract}
The implementation of the national strategy of Guangdong, Hong Kong and Macao Great Bay Area has put forward higher requirements for flood control and security in the Pearl River Delta. In this paper, region protected by Zhongshan and Zhuhai dike, which is the Qianshan River Basin, is selected as the typical area of Pearl River Delta. The flood control security of this regional is affected by flood upstream, local rainstorm and tidal level downstream. For this region, a coupled hydrological and hydrodynamic model is built and the model parameters are calibrated by measured data in June 2008 and verified by measured data in July 2012. The calculated results match well with measured data and meet the precision requirement. This research established foundation to study flood control and security in Guangdong, Hong Kong and Macao Great Bay Area.
\end{abstract}

\section{Overview}

Located in the southcentral part of Guangdong province, the Pearl River Delta is an important part of GuangdongHong Kong-Macao Greater Bay Area (GBA), covering nine cities of Guangdong. The Pearl River Delta region collects the Xijiang, Beijiang, Dongjiang Rivers and all tributaries of the delta, forming a water system pattern of "rivers converging and eight outlets going to the sea". The river network area is one of the most complex river network areas in the world for its crisscross and interconnected the water flow. The Pearl River Delta (PRD) is one of the most complex river network areas in the world. Commonly influenced by upstream flood, local rainstorm and downstream storm surge in flood season, it is prone to disaster. By the end of 2018, the total population of GBA reached 71.16 million, with a GDP of 11 trillion yuan. The nine cities in Guangdong province carried about $55.5 \%$ of the population of Guangdong Province with about $30.5 \%$ of the land area, creating about $83.3 \%$ of the GDP of Guangdong Province, with the urbanization rate of over $85 \%$, which play an important role in the economic and social development of Guangdong Province and even the whole country. However, the existing flood control (tide) capacity of the city is only to resist the flood with a return period of 50-200 years. There is still a gap between the ability of flood control, disaster reduction and safety protection and the national strategic demand, which affects the pace of building GBA in the Pearl River Delta.

Flood control and drainage decision support system is an important non engineering measure for flood disaster prevention and control, and flood risk analysis is an important part of decision support system. The method of numerical simulation is often used in flood analysis, which covers the calculation of runoff and concentration and the calculation of flood routing. The hydrodynamics coupling model can establish the hydraulic connection between the basin and the river, and can carry out hydrological simulation and forecast more precisely ${ }^{[1]}$, which is the current research hotspot. Many scholars have studied the hydrodynamics coupling model ${ }^{[1-2]}$, and many scholars have carried out theoretical research on hydrodynamics model ${ }^{[3-11]}$, and have carried out full application research on this basis ${ }^{[8-}$ ${ }^{21]}$.

Chen Ganggang et al. ${ }^{[7,14]}$ studied the theoretical framework of the coupling model of hydrology, hydrodynamics and water quality, and based on the framework, constructed one-and-two dimensional nested mathematical models of the middle reaches of the Huai River, and carried out verification calculation. The results show that the model can be used to simulate the change of water quantity and quality of large river network controlled by sluice. Lian et al. ${ }^{[13]}$ built a hydrodynamics coupling model to simulate the runoff of Illions basin in the United States. The results show that the accuracy of the coupling model is higher than that of using the hydrological model alone. Zhu Minzhe et al. ${ }^{[15]}$ constructed a hydrological and hydrodynamic model for the main stream of the Huai River. In the distributed framework, the node water level has been taken as the basic variable, and the coupling implicit solution of the whole basin flow has been carried out, and good results were obtained. CHEN et al. ${ }^{[18]}$ combined the storm water management model (SWMM) with the shallow water model (SWM), and applied the verified model to Haidian island to study the inundation response under the rainstorm mode of Haidian island. The research

\footnotetext{
* Corresponding author: xj_em@126.com
} 
results show that the coupling model can better predict the rainstorm flood, and different rainstorm modes will lead to different submergence modes.

A large number of successful applications of hydrodynamics model show that the model has high application value for flood simulation of river basin, region and city, and is of great significance for flood control and security of river basin, region and city. The purpose of this paper is to select a typical demonstration area in the Pearl River Delta region, and build a hydrodynamics coupling model, which will lay a foundation for the follow-up study on the coordination of flood control and drainage of river basins, regions and cities and the construction of flood control and drainage decision support system.

\section{Selection of Typically Demonstrated Areas}

Through constant efforts, the Pearl River water conservancy commission, the water administrative departments and emergency management departments of governments at all levels have built a flood control engineering system of "combining dike with reservoir, mainly discharging, storing and discharging at the same time", dampproof engineering system combining dike and sluice, drainage engineering system of interception, storage and drainage of seepage, and flood control non engineering system focusing on prevention. After years of "joint enclosure and sluice construction", relatively independent polder areas have been formed in the Pearl River Delta, including Jingfeng, qiaosang, Zhongshun, Jiangxin, Foshan dike, Zhongzhu joint enclosures and sluice constructions, initially forming a flood control (tide) drainage pattern of united enclosure to resist the outside flood tide, enclosure reservoirs and sluice pumps. With the continuous expansion of the Pearl River Delta urban agglomerations, the scale of centralized drainage in the surrounding area is becoming larger and larger. The flood control (tide) drainage of river basins, regions and cities affects each other and the contradiction is increasingly prominent. According to the characteristics of flood control and waterlogging drainage in the Pearl River Delta, Zhongzhu joint enclosure in Qianshanhe basin is selected as the typical demonstration area of the Pearl River Delta to carry out the hydrodynamics coupling model research, which lays the foundation for the follow-up study on the coordination of flood control and drainage and the construction of flood control and drainage decision-making support system in the basin, region and town.

Zhongzhu joint enclosure in Qianshanhe basin is located on the east bank of Modaomen, the main stream of Xijiang River in the Pearl River Delta, with a catchment area of $342.40 \mathrm{~km}^{2}$. It involves the rapid development of urbanization in Zhuhai and Zhongshan, with urbanization rates of $89.37 \%$ and $88.28 \%$ respectively. The demonstration area is threatened by the flood on the main stream of Xijiang River and attacked by typhoon surge below. The flood tide disasters are frequent and the causes are complex.
The water system in the demonstration area is well developed with crisscross rivers. The longest river is Qianshan River. There are relatively large rivers in Zhongshan City, such as MaoWan River, West irrigation canal, Tanzhou River and East irrigation canal. The main rivers in Zhuhai City are Hongwan River and Guangchang River. The water system of Zhongzhu joint enclosure in Qianshanhe basin is shown in Figure 1.

The current flood control (tide) and drainage engineering system in the demonstration area is composed of levees, sluices, pumping stations and reservoirs. There are 8 reservoirs, more than 30 sluices and more than 50 pumping stations. The Waijiang dike and 7 gates form the United enclosure flood control (tide) engineering system, and the control sluice, drainage pump station and reservoir constitute the drainage engineering system. The rainstorm flood in the surrounding areas (in the enclosure) is discharged to the inland river, and the waterlogged water is discharged to Modaomen, Hongwan and Wanchai waterways through 7 gates in Zhongzhu joint enclosure, which can be found in Table 1 with the basic information of the 7 gates.

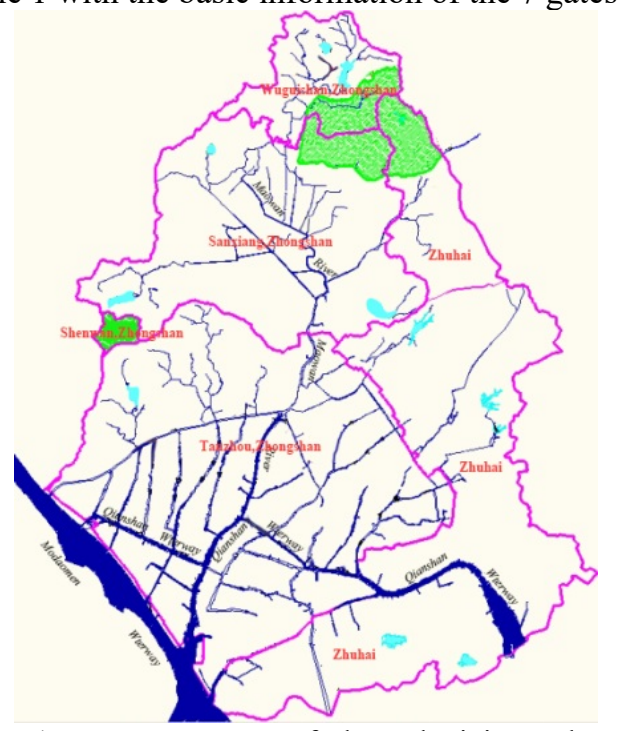

Figure 1 water system map of Zhongzhu joint enclosure in Qianshanhe basin

The current flood control (tide) and drainage engineering system in the demonstration area is composed of levees, sluices, pumping stations and reservoirs. There are 8 reservoirs, more than 30 sluices and more than 50 pumping stations. The Waijiang dike and 7 gates form the United enclosure flood control (tide) engineering system, and the control sluice, drainage pump station and reservoir constitute the drainage engineering system. The rainstorm flood in the surrounding areas (in the enclosure) is discharged to the inland river, and the waterlogged water is discharged to Modaomen, Hongwan and Wanchai waterways through 7 gates in Zhongzhu joint enclosure.

Table 1 basic information of sluice

\begin{tabular}{ccccc} 
sluice name & river & $\begin{array}{c}\text { gates } \\
\text { number }\end{array}$ & $\begin{array}{c}\text { total net width } \\
\text { of gate }\end{array}$ & $\begin{array}{c}\text { elevation } \\
\text { gate floor }\end{array}$ \\
\hline Ma Jiao & West Main & 4 & 36 & -3
\end{tabular}




\begin{tabular}{|c|c|c|c|c|}
\hline sluice & canal & & & \\
\hline $\begin{array}{l}\text { Lianshiwan } \\
\text { sluice }\end{array}$ & $\begin{array}{l}\text { Lianshiwan } \\
\text { tidal bore }\end{array}$ & 6 & 72 & -3 \\
\hline $\begin{array}{l}\text { Lantern } \\
\text { sluice }\end{array}$ & $\begin{array}{l}\text { Denglong tidal } \\
\text { bore }\end{array}$ & 2 & 20 & -3 \\
\hline $\begin{array}{l}\text { Dayongkou } \\
\text { sluice }\end{array}$ & Da tidal bore & 12 & 170.4 & -3.5 \\
\hline $\begin{array}{l}\text { Guangchang } \\
\text { sluice }\end{array}$ & $\begin{array}{l}\text { Zhumu tidal } \\
\text { bore }\end{array}$ & 3 & 24 & -3 \\
\hline $\begin{array}{l}\text { Hongwan } \\
\text { sluice }\end{array}$ & $\begin{array}{l}\text { Hongwan tidal } \\
\text { bore }\end{array}$ & 5 & 50 & -2.8 \\
\hline $\begin{array}{l}\text { Shijiaozui } \\
\text { sluice }\end{array}$ & $\begin{array}{l}\text { Qianshan } \\
\text { waterway }\end{array}$ & $39+8$ & $121+40$ & -3.5 \\
\hline
\end{tabular}

The flood control and drainage in the demonstration area affect each other. The contradiction between flood control (tide) and drainage is prominent in the upstream, downstream and left and right banks. The governance needs are very urgent, which draws high public attention. The outline of Development Plan for Guangdong Hong Kong Macao Bay Area has clearly proposed "building and improving flood control (tide) and drainage systems in Macao, Zhuhai, Zhongshan, etc., and effectively solve the urban waterlogging problem", so as to solve the flood control of Qianshanhe basin Flood (tide) drainage. It is not only the need to ensure the smooth implementation of the national strategy of Guangdong, Hong Kong and Macao Bay area, but also the need to fully reflect the superiority of "One Country, Two Systems".

\section{Hydrodynamics Coupling Model of Typically Demonstrated Areas}

The research area is Zhongzhu joint enclosure in Qianshanhe basin, and the key areas are Tanzhou town and Zhuhai area. There are both mountainous areas and plain areas in the study area, and the runoff and concentration patterns are diverse. The mountain area model is constructed separately in the surrounding mountainous area, and the runoff calculated by the mountain model is added to the corresponding river section; the plain area model is constructed in the plain area, with reference to the method in reference [3]. One dimensional hydrodynamic model is used to calculate the river channel within the enclosure, and the farmland storage area is set as the regulation and storage node, and the zero-dimensional model is used to simulate ${ }^{[3]}$. The overtopping flow is regulated and stored during the flood period. The sluice and other engineering structures are generalized as contact elements and simulated by hydrodynamic method.

\subsection{Generalization of Hydrological Model}

\subsubsection{Hydrological Model of Hilly Area}

According to the topographical and hydrometeorological conditions of Zhongzhu joint enclosure in Qianshanhe basin, the hilly area is divided into 196 large and small regions, and the hydrological model of Xin'an River is constructed in a generalized way. Due to the lack of measured data, the parameters of hydrological model in hilly area are selected according to the parameters of adjacent areas. The runoff of some hydrological models in hilly area flows into the downstream hilly area, and the runoff from the most downstream hilly area directly flows into the corresponding area of river section.

\subsubsection{Hydrological Model of Plain Area}

There is no uniform outlet for runoff and runoff in plain river network area, so the unit hydrograph of mountain area cannot be calculated as the hydrological model of mountainous area. In this paper, according to the geometric properties of confluence area and the distribution characteristics of river network, the river network polygon is divided as the basic unit in the study of plain area confluence. According to the characteristics of diversity and uneven distribution of underlying surface in Zhongzhu Lianwei plain of Qianshanhe basin, four different underlying surfaces were generalized in the plain area of $160 \mathrm{~km}^{2}$, which are the water surface of $20 \mathrm{~km}^{2}$, paddy field of $40 \mathrm{~km}^{2}$, dry land of $25 \mathrm{~km}^{2}$ and urban construction land of $75 \mathrm{~km}^{2}$. The water yield flows into the river network through the confluence unit hydrograph. A total of 34 river network polygons are generated in the river network area of Zhongzhu joint enclosure plain in Qianshanhe basin. The results of hydrological model generalization are shown in Figure 2.

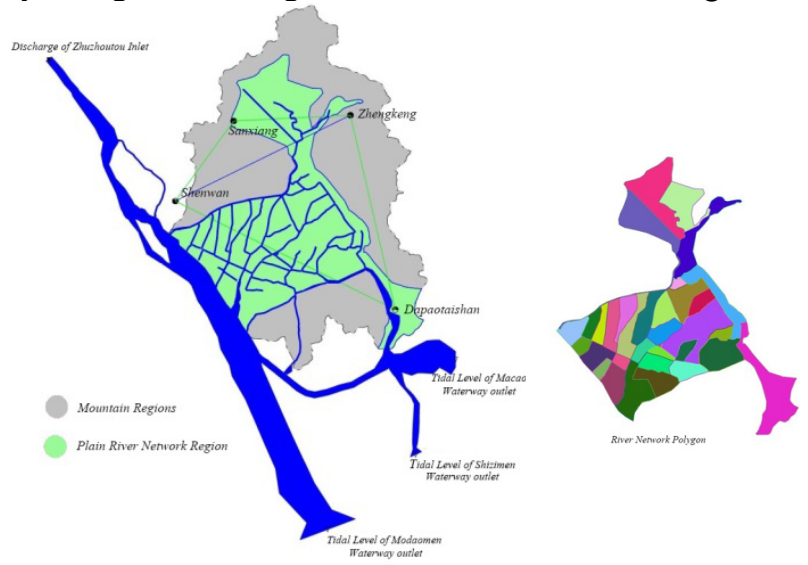

Fig. 2 schematic diagram of model generalization

\subsection{Generalization of Hydrodynamic Model}

\subsubsection{Zero-Dimensional Regional Flow Simulation}

In this study, a large number of farm land in Taizhou, Zhongzhu joint enclosure, Qianshanhe basin is generalized as zero-dimensional element simulation, and connected with the main stream channel by setting wide crested weir. The zero-dimensional regional flow simulation is mainly based on the principle of water balance. The algebraic sum of the flow in and out of the area is equal to the change of the regional storage volume in a certain period of time.

$$
\sum Q=A(Z) \frac{Z-Z_{0}}{\Delta t}
$$


In the formula, $\Sigma Q$ is the algebraic sum of the inflow and outflow of the regulation and storage area; $A(Z)$ is the area of the storage area corresponding to the water level $Z ; \Delta t$ is the time step; $Z_{0}$ and $Z$ are the water levels at the beginning and the end of the calculation period respectively.

\subsubsection{River Flow Simulation}

In Qianshanhe basin, a one-dimensional model is adopted for the river course within the scope of Zhongzhu joint enclosure and sluice construction. The governing equations of the model are as follows:

Continuity equation:

$$
\frac{\partial Z}{\partial t}+\frac{1}{B} \frac{\partial Q}{\partial x}=q_{L}
$$

Equation of motion:

$$
\frac{\partial Q}{\partial t}+\frac{\partial}{\partial x}\left(\frac{Q^{2}}{A}\right)+g A \frac{\partial Z}{\partial x}+g A \frac{Q|Q|}{K^{2}}=0
$$

In the formula, $Z$ is the water level; $Q$ is the crosssection flow of the river; $B$ is the surface river width; $\mathrm{q}_{\mathrm{L}}$ is the side inflow; $A$ is the discharge area; $K$ is the discharge modulus, which is calculated by Chezy formula; $G$ is the acceleration of gravity.

The governing equations are discretized and linearized by the Preissmann four-point implicit difference scheme, and then solved by the double pursuit method.

\subsubsection{Simulation of Engineering and Other Related Elements}

In Qianshanhe basin, the flow movement simulation of Zhongzhu joint enclosure and sluice construction is composed of zero dimensional elements and onedimensional river channel. The connection relationship between one-dimensional channel and zero-dimensional regulation and storage elements is constructed by using generalized weir and sluice. There are two flow patterns of free outflow and submerged outflow in the connection elements, which are calculated by weir flow formula.

Free outflow:

$$
Q=m B \sqrt{2 g H_{0}}
$$

Submerged outflow:

$$
Q=\phi_{m} B h_{s} \sqrt{2 g\left(Z_{a}-Z_{b}\right)}
$$

In this formula, $B$ is weir width; $Z_{d}$ is weir crest elevation; $Z_{a}$ is weir upper water level; $Z_{b}$ is weir lower water level; $Z_{0}=Z_{a}-Z_{d}, \mathrm{H}_{\mathrm{s}}=Z_{b}-Z_{d} . M$ is the flow coefficient of free outflow, generally taken as $0.325-0.385 ; \phi_{m}$ is the discharge coefficient of submerged outflow, generally taken as 1.0 .

\subsection{Model Calibration and Verification Calculation}

The whole model consists of Waijiang River, zhuzhoutou and shuihaikou. The input of the model includes boundary conditions and rainfall data from rainfall stations. The upstream boundary is given the discharge of zhuzhoutou, and the downstream boundary is given the tidal level of Modaomen waterway, shizimen waterway and Macao waterway. The rainfall stations include Sanxiang, Zhengkeng, Dabaotai mountain and adjacent Shenwan in the Pearl River Basin Hydrological model calculation have been carried out. Without flow station in Zhongzhu joint enclosure of Qianshanhe basin or measured discharge data, it is difficult to calibrate and verify the hydrological model. Therefore, the whole coupling model is verified by the water level of water level monitoring points in Zhongzhu joint enclosure of Qianshanhe basin.

There are 11 water level monitoring points in zhujoint enclosure and sluice construction of Qianshanhe basin. According to the calculated hydrological series and corresponding data, hydrological monitoring points are selected to calibrate and verify the model. The model is calibrated by the precipitation in June 2008 and the corresponding water level, and verified by the precipitation and corresponding water level in July 2012. Among the two typical precipitation events, the rainfall in June 2008 is larger, close to the magnitude of 5-year return period.

The precipitation in June 2008, and the water level calibration results of Zhongzhu joint enclosure and sluice construction of outside Majiao, outside and inside Dayongkou, Anfu and Tanzhou in Qianshanhe basin are shown in Table 2. The water level process calculated by the model and the measured water level process are shown in Figure 3.

The precipitation in July 2012, the verification results of water level at dayongkou, shijiaozui, Longtang and Tanzhou in Zhongzhu joint enclosure of Qianshanhe basin are shown in Table 3. The water level process calculated by the model and measured water level process are shown in Figure 4.

According to the statistical results, most of the interpolation between the calculated water level and the measured water level is within $0.07 \mathrm{~m}$, which meets the requirement that the error of peak valley value of tide level in Code for Calculation of Hydraulic Engineering and Water Conservancy (SL 104-2015) is not more than $10 \sim 20 \mathrm{~cm}$. The calculation process of tide level is basically consistent with the measured process, and the phase error is less than $1 \mathrm{~h}$, which meets the requirements of code for calculation of hydraulic engineering and water conservancy (SL 104-2015) The results show that the phase error is less than 1.5h in (SL 104-2015), the parameters calibrated are suitable, and the calculation results reach the engineering accuracy, which can be used for engineering research and calculation.

Tab. 2 calibration results of maximum water level in Zhongzhu joint enclosure of Qianshanhe basin (June 2008)

\begin{tabular}{cccc}
\hline Site & $\begin{array}{c}\text { Measured } \\
\text { Value }\end{array}$ & $\begin{array}{c}\text { Calculated } \\
\text { Value }\end{array}$ & D-Value \\
\hline $\begin{array}{c}\text { Outside Ma } \\
\text { Jiao }\end{array}$ & 1.45 & 1.50 & 0.05 \\
$\begin{array}{c}\text { Outside the } \\
\text { mouth of }\end{array}$ & 1.47 & 1.49 & 0.02
\end{tabular}




\begin{tabular}{cccc}
$\begin{array}{c}\text { Dayong } \\
\text { In the mouth } \\
\text { of Tai Chung }\end{array}$ & 0.66 & 0.73 & 0.07 \\
$\begin{array}{c}\text { Inside Shijiao } \\
\text { Tsui }\end{array}$ & 0.60 & 0.72 & 0.12 \\
Anfu & 0.66 & 0.73 & 0.07 \\
Tanzhou & 0.72 & 0.78 & 0.06 \\
\hline
\end{tabular}

Table 3 verification results of the highest water level of Zhongzhu joint enclosure in Qianshanhe basin (July 2012)

\begin{tabular}{cccc}
\hline Site & $\begin{array}{c}\text { Measured } \\
\text { Value }\end{array}$ & $\begin{array}{c}\text { Calculated } \\
\text { Value }\end{array}$ & D-Value \\
\hline $\begin{array}{c}\text { Outside Ma Jiao } \\
\text { Outside the } \\
\text { mouth of }\end{array}$ & 2.13 & 2.25 & 0.12 \\
$\begin{array}{c}\text { Dayong } \\
\text { In the mouth of } \\
\text { Tai Chung }\end{array}$ & 2.25 & 2.26 & 0.01 \\
$\begin{array}{c}\text { Inside Shijiao } \\
\text { Tsui }\end{array}$ & 0.78 & 0.77 & -0.01 \\
$\quad \begin{array}{c}\text { Anfu } \\
\text { Tanzhou }\end{array}$ & 0.78 & 0.77 & -0.01 \\
\hline
\end{tabular}

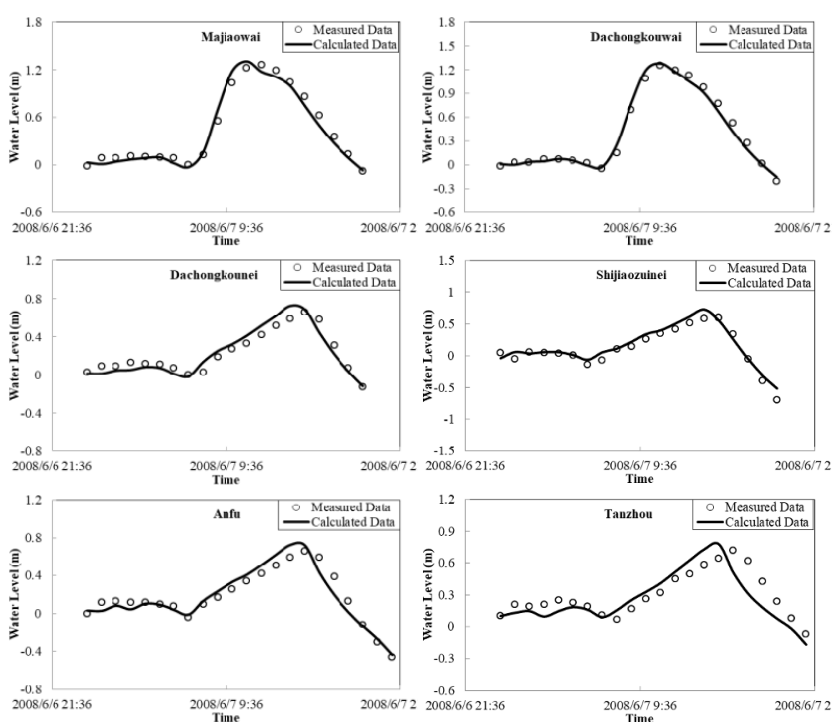

Figure 3 Calibration hydrograph of rainfall water level in June 2008

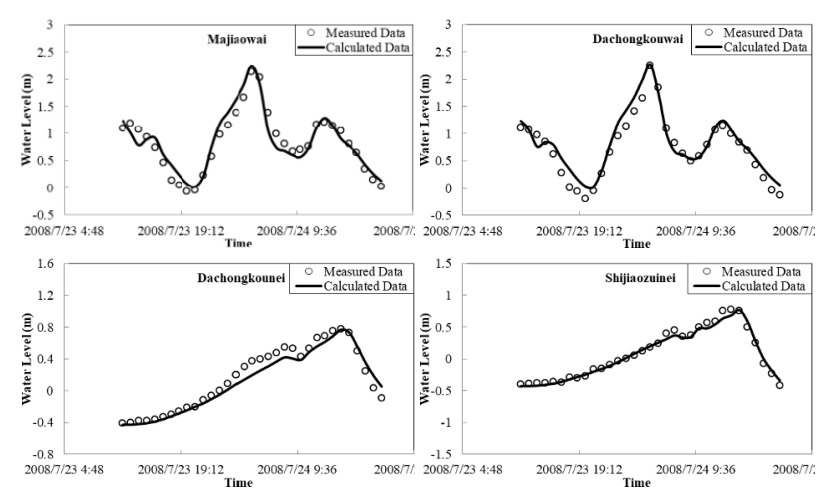

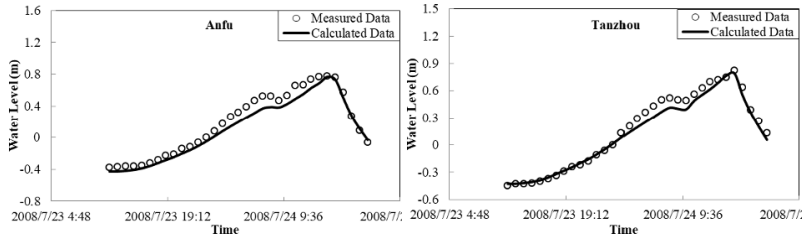

Figure 4 validation hydrograph of rainfall water level in July 2012

\section{Conclusion \& Prospect}

The results show that the model can well simulate the runoff and runoff process in the typical demonstration area of the Pearl River Delta, and can be applied to the study on the coordination of flood control and drainage between the basin and the region. In Qianshanhe basin, there is a lack of measured discharge data in the Pearl River Basin. The parameters of the hydrological model used in this study are the conventional parameters in the southern humid area, and the accuracy of the hydrological model needs to be further evaluated. In addition, the two-dimensional and pipe-network types have not been applied in the model, so it is unable to evaluate the inundation impact of urban areas. In the future, two-dimensional urban regional model and urban rainwater pipe network model will be introduced to comprehensively simulate the flood production and concentration process in river network, which can provide technical means for flood forecasting and engineering management in the typically demonstrated areas.

This research has been financially supported by the National Key Research and Development Program of China (2018YFC1508200).

\section{References}

1. Zeng ZQ, Yang MX, Lei XH, et al. (2017) A Review of Hydrological-Hydrodynamic Coupling Models for River-Basin Systems. China Rural Water and Hydropower, (9): 72-76.

2. Song LX, Xu ZX. (2019) Coupled hydrologichydrodynamic model for urban rainstorm water logging simulation:recent advances. Journal of Beijing Normal University(Natural Science), 55(05):581-587.

3. Wang CH, Li GC. (1996) The modelling of basin flood. Journal of Hydraulic Engineering, (03): 44-50.

4. Wang CH, Wang Juan, Cheng H, et al. (2007) Numerical simulation of runoff yield and confluence in plain area. Journal of Hohai University(Natural Sciences), (06):19-24.

5. Wu ZH, Wang CH, Li SJ, et al. (2014)Optimization Method of Concentration Unit Hydrograph on Plain River Network Region and Its Application. Water resources and power, 032(001):21-24.

6. Paiva R C D, Collischonn W, Tucci C E M. (2011) Large scale hydrologic and hydrodynamic modeling using limited data and a GIS based approach[J]. Journal of Hydrology, 406(3-4): 170-181. 
7. Chen LG, Shi Y, Qian X, et al. (2014) Hydrology, hydrodynamics, and water quality model for impounded rivers: I:Theory*. Advances In Water Science, 25(04): 534-541.

8. Han C, Mei Q, Liu SG, et al. (2014) Research and application on a coupled hydrological and hydrodynamic model in plain tidal river network. Chinese Journal of Hydrodynamics, (6): 706-712.

9. Lai ZQ. (2017) Distributed Hydrologic Modeling in Plain River Network Region.Nanjing Normal University.

10. Chen WJ. (2019) Urban Flood Hydrological and Hydrodynamic Model Construction and Flood Management Key Issues Exploration. South China University of Technology.

11. Mei C. (2019) Development of a coupled urban hydrological- hydrodynamic model and its application. China Institute of Water Resources \& Hydropower Research (IWHR).

12. Thompson J R, Srenson H R, Gavin H, et al. (2004) Application of the coupled MIKE SHE/MIKE 11 modelling system to a lowland wet grassland in southeast England. Journal of Hydrology, 293(1-4): $151-179$.

13. Lian Y, Chan I C, Singh J, et al. (2007) Coupling of hydrologic and hydraulic models for the Illinois River Basin[J]. Journal of Hydrology, 344(3): 210222.

14. Chen LG, Shi Y, Qian X, et al. (2014) Hydrology, hydrodynamics, water quality model for impounded rivers: II: Application*. Advances In Water Science, 25(06): 856-863.

15. Zhu MZ, Wang CH, Liu SG. (2014) Study on distributed and coupled hydrological and hydrodynamic numerical model for main stream of Huaihe River. Water Resources and Hydropower Engineering 45(8): 27-32.

16. Yuan XM, Pang JL, Tian FC, et al. (2016) Application of multi-breach river network coupling model in flood analysis of flood control protection Zone. Journal of Water Resources \& Water Engineering, 27(01): 128-135.

17. Wu XS , Wang ZL, Guo SL, et al. (2017) Scenariobased projections of future urban inundation within a coupled hydrodynamic model framework: A case study in Dongguan City, China. Journal of Hydrology, 547:428-442.

18. Chen WJ, Huang GR, Zhang H, et al. (2018) Urban inundation response to rainstorm patterns with a coupled hydrodynamic model: A case study in Haidian Island, China. Journal of Hydrology, 564:1022-1035.

19. Ye CL, Xu ZX, Lei XH, et al. (2019) Coupling simulation of hydrological and hydrodynamics processes for urban river networks based on InfoWorks: case of the urban area and the northeast mountainous area in Fuzhou City. Journal of Beijing Normal University(Natural Science), 55(05): 609-
616.

20. Luo HW, Chen WJ, Li ZW, et al. (2019) Flood simulation of Donghaochong Basin in Guangzhou City based on coupled hydrodynamic model. Journal of Water Resources \& Water Engineering, 30(03): 46-52+65.

21. Yu FQ, Yu JS, Jiang WW 1, et al. (2019) Flood inundation simulation based on coupled hydrologichydrodynamic model. South-to-North Water Transfers and Water Science \& Technology, 17(05):37-43. 